\title{
Experiências de (in)acessibilidade vivenciadas por pessoas com lesão medular*
}

\author{
Aline Gabriela Bega Ruiz ${ }^{1}$, Mayckel da Silva Barreto², Marcelle Paiano ${ }^{3}$, \\ Jussara Simone Lenzi Pupulim ${ }^{4}$, Maria das Neves Decesaro ${ }^{5}$, Sonia Silva Marcon ${ }^{6}$
}

\section{RESUMO}

O objetivo foi apreender as experiências de (in)acessibilidade vivenciadas por pessoas com lesão medular. Pesquisa descritiva exploratória de abordagem qualitativa. Os dados foram coletados no período de janeiro a junho de 2016, por meio de entrevista com 23 pessoas com lesão medular, localizadas a partir das equipes da Estratégia Saúde da Família e na Associação de Apoio ao Esporte Adaptado e submetidos à análise de conteúdo temática. Emergiram duas categorias, as quais mostram que as pessoas com lesão medular enfrentam dificuldades para realizar atividades cotidianas com autonomia, insuficiência e/ou deficiência na acessibilidade e no apoio familiar e social. Contudo, a prática esportiva e uma atuação familiar ativa podem constituir incentivo eficaz à convivência social e igualitária. A implementação adequada das políticas públicas de inclusão e acessibilidade já existentes facilitaria e permitiria às pessoas com lesão medular, maior socialização e participação em atividades relacionadas à saúde e ao esporte adaptado.

Descritores: Pessoas com Deficiência; Apoio Social; Paraplegia; Enfermagem em Saúde Comunitária.

\footnotetext{
* Artigo extraído da Dissertação de Mestrado intitulada "Vivências cotidianas da pessoa com lesão medular" apresentada ao Programa de PósGraduação em Enfermagem da Universidade Estadual de Maringá em 2017.

${ }^{1}$ Enfermeira, Mestre em Enfermagem. Discente do Programa de Pós-Graduação em Enfermagem da Universidade Estadual de Maringá. Maringá, PR, Brasil. E-mail: aline.bega@hotmail.com.

${ }^{2}$ Enfermeiro, Doutor em Enfermagem. Professor na Faculdade de Filosofia, Ciências e Letras de Mandaguari. Mandaguari, PR, Brasil. E-mail: mayckelbar@gmail.com.

${ }^{3}$ Enfermeira, Doutora em Enfermagem. Professora Adjunta na Universidade Estadual de Maringá. Maringá, PR, Brasil. E-mail: marcellepaiano@hotmail.com.

${ }^{4}$ Enfermeira, Doutora em Enfermagem. Professora Associada na Universidade Estadual de Maringá. Maringá, PR, Brasil. E-mail: jslpupulim@bol.com.br.

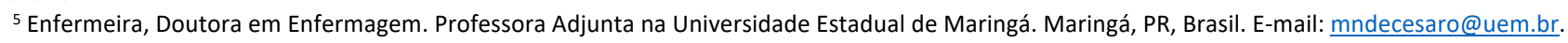

${ }^{6}$ Enfermeira, Doutora em Filosofia da Enfermagem. Professora Titular na Universidade Estadual de Maringá. Maringá, PR, Brasil. E-mail: soniasilva.marcon@gmail.com.
}

Artigo recebido: 16/06/2018.

Artigo aprovado: 03/10/2018.

Artigo publicado: 31/12/2018.

\section{Como citar esse artigo:}

Ruiz AGB, Barreto MS, Paiano M, Pupulim JSL, Decesaro MN, Marcon SS. Experiências de (in)acessibilidade vivenciadas por pessoas com lesão medular. Rev. Eletr. Enf. [Internet]. 2018 [acesso em:

];20:v20a58. Disponível em: https://doi.org/10.5216/ree.v20.53538. 


\section{INTRODUÇÃO}

A lesão da medula (LM) é responsável por desencadear um quadro de doença crônica e deficiência física, implicando alterações neurológicas significativas ${ }^{(1)}$. Todos os anos até meio milhão de pessoas em todo o mundo são acometidas, sendo mais frequente em adultos jovens e do sexo masculino e em decorrência de trauma ${ }^{(2)}$.

Destarte, a LM atinge a vida da pessoa em diferentes aspectos, principalmente, nos âmbitos social, psicoemocional e na aceitação da autoimagem corporal, pois envolve enorme carga de incapacidade e diminuição da qualidade de $v{ }^{(1-2)}$. As pessoas acometidas geralmente deparam-se com necessidades de saúde maiores do que outros indivíduos, pois apresentam condições e/ou agravos que são influenciados pelo processo de adaptação social e acessibilidade ${ }^{(1)}$.

A maior parte das pessoas com LM vive em uma sociedade excludente e em um contexto social que oprime suas especificidades, visto que, a falta de acessibilidade dificulta o bem-estar, a adaptação e prejudica a autoestima dessas pessoas ${ }^{(3)}$. Nesse sentido, torna-se imprescindível o desenvolvimento de ações coletivas do poder público e da comunidade para diminuir as barreiras arquitetônicas e a segregação social ${ }^{(1)}$.

O Ministério da Saúde, em atenção às questões que permeiam e condicionam a exclusão social das pessoas com LM, formulou, há quase uma década, o guia "Atenção à Saúde da Pessoa com Deficiência", destacando a necessidade de favorecer a autonomia e mobilidade das pessoas com LM, para que elas possam se movimentar com segurança, confiança e maior comodidade. Ressalta ainda a acessibilidade como forma de respeito e busca pela diminuição das barreiras que são enfrentadas cotidianamente, destacando o preconceito e a discriminação(4).

A legislação brasileira assegura à pessoa com LM diversos direitos, incluindo a promoção da acessibilidade e benefícios previdenciários. Porém, empiricamente, esses direitos ainda não são suficientes para a integração igualitária das pessoas com LM à sociedade civil. A possível sensibilização da população acerca dos desafios que estas pessoas enfrentam em sua realidade cotidiana pode desencadear, a médio e longo prazo, maior preocupação com aspectos relacionados à acessibilidade de locais públicos e privados, por parte da sociedade civil e organizada, cumprindo desta forma direitos já legalmente garantidos ${ }^{(5)}$.

Entretanto, a acessibilidade de pessoas com LM não tem constituído foco das pesquisas de enfermagem, o que preocupa, pois o enfermeiro como integrante da equipe de saúde, deve buscar conhecimentos e evidências científicas e a partir delas propor estratégias que favoreçam a adaptação do meio físico, a fim de promover acesso seguro a estas pessoas ${ }^{(6)}$.

Investigar a percepção das pessoas com LM a respeito da acessibilidade arquitetônica e como elas se sentem perante a vida em sociedade, no meio familiar e entre amigos, é uma maneira de dar voz e visibilidade a elas. Assim, o objetivo desta pesquisa foi apreender as experiências de (in)acessibilidade e vivenciadas por pessoas com lesão medular.

\section{MÉTODO}

Pesquisa descritiva exploratória, de abordagem qualitativa realizada com pessoas com LM, residentes em município de médio porte no noroeste do estado do Paraná. À época do estudo, contava com uma população de 403.000 habitantes, 74 equipes da Estratégia Saúde da Família (ESF) alocadas em 34 Unidades Básicas de Saúde, com $63,3 \%$ da população coberta pela $\operatorname{ESF}^{(7)}$. 
Os dados foram coletados de janeiro a junho de 2016, por meio de entrevista. Os participantes foram 23 pessoas com LM, localizadas com auxílio das equipes da ESF (11) e na Associação de Apoio ao Esporte Adaptado da Universidade Estadual local (12). Os critérios de inclusão foram: apresentar LM há mais de dois anos e ter 18 anos ou mais, sendo excluídos os não localizados após três tentativas de busca.

O primeiro contato com os usuários das Unidades Básicas de Saúde foi intermediado pelo agente comunitário de saúde e realizado, pessoalmente ou por telefone. Já com os desportistas foi realizado pessoalmente em visita à quadra de esporte. As entrevistas, previamente agendadas, foram realizadas no domicílio ou em local reservado próximo a quadra de esportes, tiveram duração média de uma hora e meia e foram gravadas em aparelho digital. Elas foram guiadas pela questão norteadora: Fale-me das mudanças em sua vida após a LM. A busca por informações ocorreu até o momento em que os dados começaram a se tornar repetitivos e o objetivo da pesquisa respondido.

Todas as entrevistas foram transcritas na íntegra e submetidas à análise de conteúdo, modalidade temática, seguindo as três etapas propostas ${ }^{(8)}$. Na pré-análise foi realizada leitura flutuante das entrevistas, seguido da exploração do material com leitura minuciosa e exaustiva do conteúdo impresso. Após, foi realizada a codificação das mensagens por meio de cores, com apreensão dos núcleos de sentido, agrupando-os de acordo com suas similaridades $^{(8)}$. Deste processo analítico emergiram duas categorias temáticas: Dificuldades para locomover-se e integrar-se; e Segregação social x integração com o passar do tempo, as quais foram discutidas à luz da literatura científica.

Foram respeitados todos os preceitos éticos da Resolução 466/12 e o projeto aprovado pelo Comitê de Ética da Universidade signatária (Parecer no 1.328.940/2015). Os excertos das falas dos participantes estão identificados com a letra "P" ("Participante"), seguida de um número arábico indicativo da ordem de realização das entrevistas, das letras "M" (mulher) ou "H" (homem), outro número indicativo da idade e o último do tempo da LM.

\section{RESULTADOS}

Os 23 entrevistados tinham idade entre 23 e 58 anos, 16 deles eram do sexo masculino, oito eram solteiros, nove casados, cinco separados e um viúvo; e sete tinham mais de oito anos de estudo. Em relação à atividade laboral, cinco mantinham vínculo empregatício, enquanto 18 recebiam benefícios do governo. 0 tempo transcorrido da lesão variou de 2,7 a 33 anos. Quanto à etiologia, 11 sofreram acidente automobilístico (oito com motocicletas), oito foram feridos por arma de fogo, dois sofreram queda de altura, um foi vítima de atropelamento e outro de tumor na região cervical.

Todos os entrevistados referiram, no mínimo, uma internação hospitalar em decorrência da LM. As principais causas das internações foram infecções urinárias e pulmonares, lesões por pressão e tratamentos de complicações, como a Coluna de Sharcoh. Alguns possuíam patologias concomitantes, tais como: Diabetes mellitus (duas pessoas), Hipertensão Arterial, Coluna de Sharcoh, Insuficiência Renal Crônica, Hepatite viral, Capsulite Adesiva e cálculo renal. Quinze participantes não referiram nenhum problema de saúde.

As duas categorias temáticas que emergiram serão descritas a seguir: 


\section{Dificuldades para locomover-se e integrar-se}

Ao utilizar a cadeira de rodas em locais públicos e privados, as pessoas com LM referiram a pouca acessibilidade, ainda extensivamente presente no meio social, como a dificuldade em conseguir locomover-se nas ruas e edifícios e para utilizar meios de transporte coletivo como aviões e ônibus. Isto impacta sobre suas ações e interações.

A falta de acessibilidade dentro da própria casa ou nos demais ambientes que frequentam, como casa de amigos, de familiares e outros dispositivos de convívio social acarreta nos participantes a vivência simbólica do constrangimento. Isto porque emanam significados de impossibilidade para desempenhar sua independência e autonomia em atividades simples como utilizar o banheiro ou a cozinha, ou mesmo para desfrutar da interação em momentos alegres e festivos.

Não tem adaptação nas igrejas [...] Uma vez que me deixou muito constrangida foi na casa da minha irmã no aniversário do meu pai, não tinha acessibilidade, fui no colo, sentaram-me no sofá [...] Na universidade é difícil, as calçadas são estouradas! (P5-M, 52a, LM-32a).

É difícil quando estou na casa dos outros, a porta do banheiro pequena, a cadeira não passa, alguém tem que me pegar no colo [...] fazer a rampa na cozinha aqui em casa, ocuparia espaço [...]. Conto com a ajuda do vizinho para subir $e$ descer a rampa para tomar banho (P3-H, 29a, LM-2a).

Outro problema enfrentado foi a falta de acessibilidade nas ruas, pois as calçadas são consideradas íngremes e as rampas de acesso inadequadas. Isto impedia, principalmente as mulheres, de transitarem sozinhas, visto que seis das sete entrevistadas referiram a dificuldade, impondo o auxílio de um familiar. Vale ressaltar que na periferia a situação das calçadas e ruas foi considerada ainda mais precária. Por sua vez, os relatos também mostram que vagas de estacionamento destinadas às pessoas com deficiência não são respeitadas pela sociedade.

Não faço nada sozinha. Fomos (filha) em uma loja pela calçada, um carro estacionou na calçada, atrapalha! Não ando sozinha, para subir rampa não consigo, são muito íngremes, a cadeira empina. O asfalto é cheio de buraco (P6-M, 48a, LM-8a).

Falando de acessibilidade, todos os seguimentos deixam muito a desejar! Nos bairros, nas ruas, nos postos de saúde mesmo, porque a acessibilidade é só central. (P5-M, 52a, LM-32a).

Outro aspecto apontado foram as más condições para se locomover com cadeira de rodas em aeroportos, ou para embarcar em avião ou ônibus.

No avião a comissária falou: "acho que o senhor não consegue entrar no banheiro". Uma cadeira não transita na aeronave e nem todos os aeroportos tem cadeiras especiais (P13-H, 35a, LM-18a).

Levava um cobertor dentro do ônibus, jogava em cima de mim, fazia xixi dentro de uma garrafinha d'água (P11-M, 34a, LM-7a).

Foi possível perceber com os relatos que as repartições públicas e os meios de transporte também não propiciam a mobilidade adequada, além de não permitirem privacidade para a realização de procedimentos cotidianos e necessários ao bem-estar físico, como o cateterismo vesical de alívio. Isto, em alguns casos, foi considerado pelos entrevistados como limitador para a realização de viagens, sendo que o significado de viajar, ao longo do tempo, se modificou frente a vivência de diversas dificuldades para a concretização da mesma. 


\section{Segregação social X integração com o passar do tempo}

Houve situações nas quais as pessoas com LM, se sentiam excluídas ou sofriam discriminação, por parte da sociedade de modo geral, acarretando na vivência, sentimento de tristeza. Por outro lado, algumas pessoas relataram momentos/situações em que se sentiam acolhidas, inclusas e incentivadas, o que favoreceu a recuperação de sua autonomia.

As situaações de exclusão são percebidas pelos entrevistados no olhar das pessoas, que em algumas vezes, expressam rejeição e preconceito, e em outras, curiosidade, causando-lhes desconforto e incômodo. Também foram relatadas situações em que as ações e interações sociais levavam a tratamento excludente, no qual os indivíduos se dirigiam ao acompanhante da pessoa com LM, por significarem o fato de estar em uma cadeira de rodas como interferente na capacidade intelectual e cognitiva.

O olhar é ruim, parece que estou doente, coitadinho, que dó! É estranho, criança vem e tem pai que "Não toca!" parece que sou leproso [...] é a pior sensação, pois todo mundo está olhando (P9-H, 29a, LM-10a).

Pessoas têm curiosidade, olham mesmo. E quando você está na rua e as pessoas falam "oi" (sem entusiasmo) acha que você é retardado! E quando vão conversar com a pessoa que está me empurrando?! (P11-M, 34a, LM-7a).

As percepções de exclusão envolveram as mais variadas ambiências e pessoas, como ônibus, vendedores, amigos e a população em geral. O preconceito vivenciado abrangeu, por exemplo, o desligamento e o abandono dos próprios familiares. Ações de exclusão social, acarretam às pessoas com LM experiências simbolicamente negativas que despertam a sensação de abandono, como não ser convidado para festas em família e até mesmo ser escondido por seus familiares ou pelo cônjuge.

Deixei de fazer muitas coisas. Até hoje não consigo viajar, o ônibus tem o adesivo do cadeirante, mas cadê a adaptação? Acho isso um crime! É muito constrangimento, o cobrador não querer colocar a gente para dentro, dizer que tem problema de coluna (P5-M, 52a, LM-32a).

No início era muito preconceito na família, fiquei muito tempo escondida num quarto. Porque a visão das pessoas é que tinha uma maldição na família (P5-M, 52a, LM-32a). Amo piscina, minha tia vive numa, nunca me chamou. Sei que ela acha que sou um problema. As pessoas não te chamam para mais nada, se afastam (P11-M, 34a, LM-7a). Ele (cônjuge) foi perdendo o amor. O amor era quando andava, trabalhava, dançava. De repente, me ver naquela situação, ajudou a separação (P10-M, 38a, LM-18a).

Também foram relatadas dificuldades em inserir-se no mercado de trabalho. Neste aspecto duas situações concorrem para dificultar às pessoas com LM serem integradas a sociedade: o preconceito e a falta de acessibilidade nos locais de trabalho.

Iam me contratar, fui aprovado nos testes. Trocou o gerente. Ele chamou para me conhecer, disse que tinha gostado muito, mas a vaga foi cancelada. Achei preconceito na hora que o gerente me viu na cadeira (P2-H, 26a, LM-7a).

Todo lugar que arrumei estágio, ou eles falavam que não dava por ser cadeirante, ou realmente não dava, porque é apertado, não passava nas portas. A vaga é para deficiente, mas querem aquele deficiente que anda, que só não tem um dedo (P11-M, 34a, LM-7a).

Além do modo distinto de tratamento recebido no momento de se inserirem formalmente no mercado de trabalho, também houve situações em que os próprios entrevistados, ao assumirem o papel do outro - no caso a 
sociedade excludente, preconceituosa e despreparada - se auto excluíam, deixando de participar de atividades coletivas ou mesmo de saírem de casa.

Ele (marido) me levava para os pesqueiros, eu ficava dentro do carro chorando! [...] não queria sair para rua no começo (P8-M, 35a, LM-23a).

No segundo ano de cadeira, ficava só em casa, deitado, sem vida. Tinha vergonha de mim, não era nem da cadeira [...] ia fazer fisioterapia, saia de casa bem rápido para ninguém ver. Perdi dez anos de vida me reprimindo (P17-H, 40a, LM20a)

Contudo, houve relatos de situações de inclusão, em que a comunidade, familiares e a prática esportiva incentivaram e estiveram presentes. Essas interações modificaram os significados que a LM acarreta nessas pessoas, como o preconceito, facilitando as interações sociais e o retorno às atividades cotidianas. 0 esporte em si ajudou a minimizar as dificuldades da socialização presente no início, sobretudo nos primeiros tempos após a LM.

Todos os lugares que o meu marido está, também estou. Mesmo que as pessoas não me queiram, ele me enfia. De barco! Na praia! (P7-M, 46a, LM-33a).

Quando comecei a sentar na cadeira, me levavam para barzinho, tudo quanto é lugar (amigos e família) (P12-H, 28a, LM-5a).

Não tenho mais vergonha, foi praticando esporte que ajudou (P19-H, 36a, LM-12a).

De acordo com a maioria dos relatos, os símbolos do preconceito e da discriminação estiveram presentes no cotidiano destas pessoas. Porém, com o passar do tempo, a socialização e inclusão por meio da interação com familiares, amigos e a prática esportiva propiciou a superação das mudanças advindas da lesão.

\section{DISCUSSÃO}

A acessibilidade ineficiente ou inexistente em diferentes locais fez com que as pessoas com LM se sentissem excluídas e deixassem de participar/interagir socialmente em ambientes inacessíveis e pouco inclusivos. Estudo realizado em Portugal junto a 28 pessoas com LM também evidenciou que a capacidade de locomoção delas era limitada, em decorrência da ausência de acessibilidade em ambientes diversos e/ou até mesmo em suas residências. Nesse sentido, é fundamental a adequação física às novas necessidades frente a convivência com a LM, para permitir a máxima mobilidade ${ }^{(3)}$.

Além dos buracos nas ruas, degraus, calçadas irregulares e rampas íngremes, as pessoas, em especial as mulheres, depararam-se com entulhos, carros sobre as calçadas, objetos que os impedem de locomover-se com autonomia e sozinhos. Estudo realizado em Santa Catarina com 13 indivíduos que possuíam LM também evidenciou a falta de acessibilidade; calçadas inadequadas e rampas com angulação inapropriada destacados por pessoas de ambos os sexos ${ }^{(5)}$. O Ministério da Saúde salienta que a acessibilidade significa permitir a autonomia e maior independência para essas pessoas, facilitando a retomada da identidade ${ }^{(4)}$.

Além das barreiras físicas, os relatos apontam a existência de preconceito e discriminação enfrentados diariamente. Estudo realizado com pessoas com LM em São Paulo identificou que a falta de acessibilidade e o preconceito eram os fatores mais preponderantes a serem superados para a integração social( ${ }^{(9)}$. Assim, em respeito à dignidade humana, a comunidade necessita promover acessibilidade e garantir a aplicabilidade dos 
direitos de equidade, pois todos os indivíduos merecem desenvolver seus projetos de vida com conjunturas igualitárias e com o respeito de seus semelhantes ${ }^{(10)}$.

O olhar e algumas atitudes - como se afastar ou tratar a pessoa com LM como se ela apresentasse retardo mental - caracterizam, na opinião dos participantes, símbolos sociais que representam dó e incapacidade perante a sociedade. Porém, com o passar do tempo, ao se colocarem no papel do outro, eles passavam a compreender o posicionamento da sociedade e, até mesmo, se acostumavam com tais situações. Entretanto, não deixavam de se sentir excluídos socialmente. Estudo de representações sociais revela que o estigma de não caminhar, repercute frente a sociedade, pois pode confundir o necessitar de cadeira de rodas com alguma outra deficiência/retardo mental, e isso leva a tratamentos discriminatórios aos indivíduos com $\mathrm{LM}^{(11)}$.

Nesse sentido, estudo de revisão evidenciou que a pessoa com LM depara-se com uma sociedade pouco inclusiva $^{(12)}$. Infelizmente, muitas pessoas não se colocam no papel do outro e usam vagas de estacionamento destinadas aos cadeirantes, infringindo o direito legal dessas pessoas. Por sua vez, a Constituição Brasileira salienta a importância de atuações que facilitem e adaptem os ambientes físicos para as pessoas com necessidades especiais, assim implicando em melhores condições de acessibilidade ${ }^{(13)}$.

Estes dados reforçam a lacuna mencionada no estudo realizado em Santa Catarina, no qual as pessoas com LM ressaltaram acessibilidade ineficiente em estabelecimentos comerciais e dificuldade em utilizar transportes como ônibus e aviões ${ }^{(5)}$. Desse modo, ainda existe uma generalizada falta de sensibilização da sociedade perante as necessidades singulares e, por vezes, mais elementares como locomover-se utilizando o transporte coletivo, o que pode desencadear o isolamento social, sobretudo no início da $\mathrm{LM}^{(5)}$.

Nesse sentido, estudo realizado em João Pessoa-PB, com 120 pessoas mostrou que $80 \%$ dos sujeitos com deficiência não participavam de grupos sociais, como religiosos, encontro com amigos e festas comunitárias. Em consequência da restrição ao convívio familiar, ocorreu um agravo das limitações decorrentes da deficiência, pois, a participação social ativa incentiva a retomada das atividades diárias saudáveis ${ }^{(14)}$. De acordo com a literatura, desde a primeira hospitalização deve haver esclarecimento de dúvidas e incentivo para a adaptação à sua nova condição de saúde. $O$ suporte social e familiar tem significados importantes para a superação das dificuldades advindas da LM, principalmente no início desse processo ${ }^{(15-17)}$.

Estudo desenvolvido com 210 pessoas com LM constatou, já durante a primeira internação para reabilitação, mudanças positivas na imagem corporal dos participantes, com diminuição dos níveis de depressão e ansiedade. Estes resultados levaram os autores a recomendar que todos os integrantes das equipes de saúde devem preocupar-se em desenvolver intervenções que possam colaborar para a melhoria da imagem corporal dessas pessoas ${ }^{(15)}$.

Assim, para promover a inclusão social dessas pessoas no âmbito público, privado, comunitário e familiar, parece oportuno e necessário sensibilizar a população por meio de projetos sociais e políticas de inclusão que as beneficiem diretamente e a seus familiares. Estas ações devem ser multidisciplinares e o Ministério da Saúde propõe a rede de cuidado à pessoa com deficiência com o objetivo de ampliar o acesso e qualificar o atendimento no Sistema Único de Saúde ${ }^{(1)}$.

Por sua vez, há a existência de ambientes de trabalho inapropriados para cadeira de rodas ${ }^{(18)}$, assim, o governo brasileiro criou legislação específica e instaurou o Conselho Nacional dos Direitos da Pessoa Portadora de 
Deficiência (CONADE) para fiscalizar sua implantação ${ }^{(19)}$. Porém, apesar dos avanços, muito há por fazer, pois a presença desses indivíduos no mercado de trabalho não significa, via de regra, inclusão social, e sim cumprimento da legislação. Estudo na Austrália com 250 indivíduos com LM mostrou que eles sofriam preconceito e discriminação no local de trabalho e, em alguns casos, recebiam menos, embora desempenhassem as mesmas funções que outras pessoas ${ }^{(20)}$.

Ainda nesta direção, estudo com funcionários e gestores da Universidade de São Paulo avaliou os efeitos de uma intervenção que tinha como propósito, promover reflexão crítica sobre a inclusão de pessoas com deficiência no mercado do trabalho. Os resultados mostraram que após o curso, os participantes manifestaram concepções mais favoráveis a esta participação, levando os autores a concluírem que estas reflexões podem produzir mudanças nas atitudes sociais dos empregados e da equipe administrativa, favorecendo a inclusão de pessoas com deficiência no ambiente de trabalho ${ }^{(21)}$.

Os familiares e amigos com quem interagiam e desfrutavam de atividades de lazer se afastaram, inclusive, em alguns casos, houve a separação cônjuge/namorado(a). Entretanto, a presença dessas pessoas, ofertando cuidados, dando suporte no processo de reabilitação e reinserção social, incentivando a adaptação e a atribuição de um outro significado a nova condição de vida é imprescindível ${ }^{(5,17,22)}$. Nesta direção, o esporte surge como facilitador do processo de adaptação, com melhoria na capacidade funcional, e qualidade de vida, pois promove benefícios físicos, psicológicos e de socialização(23-24).

\section{CONSIDERAÇÕES FINAIS}

Os resultados mostram que as pessoas com LM sentem dificuldades para voltar a realizar atividades cotidianas com autonomia, por falta de acessibilidade e de apoio no ambiente domiciliar e/ou social, implicando limitações para locomover-se pelas ruas ou calçadas, entrar em estabelecimentos que frequentavam anteriormente ou utilizar o transporte público. Além de se sentirem excluídos por familiares, amigos e comunidade.

Contudo, com o passar do tempo, estas limitações foram minimizadas por meio da inclusão social e acolhimento na comunidade, bem como convivência com familiares e amigos. Isto, por sua vez, possibilitou que novas atividades, como a prática esportiva, assim como, atividades outrora realizadas, passassem a fazer parte do cotidiano da pessoa com LM.

Portanto, a implementação adequada das políticas públicas de inclusão e acessibilidade já existentes permitiria a socialização comunitária, participação em atividades relacionadas à saúde e ao esporte adaptado. Os resultados ressaltam a importância da enfermagem, enquanto prática social, tomar para si a responsabilidade de atuar junto a estas pessoas, incentivando-as a lutarem por seus direitos enquanto cidadãos e por qualidade de vida no âmbito domiciliar e em sociedade.

Porém, o estudo apresenta algumas limitações, entre elas o fato dos participantes serem, em sua maioria, do sexo masculino, o que demonstra a necessidade de estudos envolvendo um maior número de mulheres, a fim de se conhecer melhor as especificidades da percepção deste público. 


\section{REFERÊNCIAS}

1. Brasil. Ministério da Saúde. Secretaria de Atenção à Saúde. Departamento de Ações Programáticas Estratégicas. Diretrizes de atenção à pessoa com lesão medular. Brasília: Ministério da Saúde [Internet].; 2013 [acesso em: 10 out 2017]. Disponível: http://bvsms.saude.gov.br/bvs/publicacoes/diretrizes atencao pessoa lesao medular.pdf.

2. Word Health Organization (WHO). International perspectives on spinal cord injury. World Health Organisation [Internet].; 2013. [acesso em: 21 maio 2018]. Disponível em: http://apps.who.int/iris/bitstream/10665/94190/1/9789241564663 eng.pdf.

3. Fontes F, Martins BS. Deficiência e inclusão social: os percursos da lesão medular em Portugal. Sociologia, Problemas e Práticas [Internet].; 2015;(77) [acesso em: 15 nov 2017]. Disponível em: http://www.scielo.mec.pt/pdf/spp/n77/n77a08.pdf.

4. Brasil. Ministério da Saúde. Secretaria de atenção à Saúde. Departamento de Ações Programáticas Estratégicas. Atenção à Saúde da Pessoa com Deficiência no Sistema Único de Saúde - SUS. Brasília: Ministério da Saúde [Internet].; 2009 [acesso em: 05 dez 2017]. Disponível em: http://bvsms.saude.gov.br/bvs/publicacoes/atencao_saude_pessoa_deficiencia_sus.pdf.

5. Cruz DM, do Nascimento LRS, da Silva DMGV, Schoeller SD. Redes de apoio à pessoa com deficiência física. Cienc. enferm [Internet].; 2015;21(1): 319-327 [acesso em: 20 jun 2017]. Disponível em: http://dx.doi.org/10.4067/S0717-95532015000100003. 6. Azevedo TR, Valdevino SC, Costa KFM, Neto JV, Lira LGRSH, Martins KP. Acessibilidade física de pessoas com deficiência em hospitais públicos. Enferm Global [Internet].; 2015; 37(1) [acesso em: 03 set 2018]. Disponível em:

http://scielo.isciii.es/pdf/eg/v14n37/pt administracion3.pdf.

7. Brasil. Ministério da Saúde. Departamento de Atenção Básica. 2018 [citado 2018 ago 31]. Cobertura da Atenção Básica. Available from: https://egestorab.saude.gov.br/paginas/acessoPublico/relatorios/relHistoricoCoberturaAB.xhtml.

8. Bardin L. Análise de conteúdo. Lisboa: Edições 70; 2016. p. 229.

9. Vasco CC, Franco MHP. Indivíduos Paraplégicos e o Significado Construído para a Lesão Medular em suas Vidas. Psicol., Ciênc. Prof [Internet].; 2017;37(1): 119-131 [acesso em: 19 dez 2017]. Disponível: http://dx.doi.org/10.1590/1982-3703000072016. 10. Sandini SP, Horst CCB. Desafios para a inclusão dos alunos com deficiência física. VOOS Rev. Polidisc [Internet].; 2014;6(2):54-62 [acesso em: 15 nov 2017]. Disponível em: http://www.revistavoos.com.br/seer/index.php/voos/article/view/308/pdf 6.

11. Costa VSP, Melo MRAC, Garanhani ML, Fujisawa DS. Representações sociais da cadeira de rodas para a pessoa com lesão da medula espinhal. Rev. Latino-Am. Enferm [Internet].; 2010;18(4):755-762 [acesso em: 12 jan 2017]. Disponível em:

http://www.scielo.br/pdf/rlae/v18n4/pt 14.pdf.

12. Coura AS, Enders BC, Menezes RMP, França ISX. Análise contextual da consulta de enfermagem na visita domiciliar às pessoas com lesão medular. Reme: Rev. Min. Enferm [Internet].; 2013;17(4):1000-1006 [acesso em: 21 fev 2017]. Disponível em:

http://www.dx.doi.org/10.5935/1415-2762.20130072.

13. Brasil. Constituição da República Federativa do Brasil. Brasília: Senado Federal;1988.

14. Holanda CMA, Andrade FUP, Bezerra MA, Nascimento JPS, Neves RF, Alves SB, et al. Redes de apoio e pessoas com deficiência física: inserção social e acesso aos serviços de saúde. Ciênc. saúde coletiva [Internet].; 2015;20(1):175-184 [acesso em: 21 ago 2017]. Disponível em: http://dx.doi.org/10.1590/1413-81232014201.19012013.

15. Diemen TV, Leeuwen CV, Nes IV, Geertzen J, Post M. Body Image in Patients With Spinal Cord Injury During Inpatient Rehabilitation. Arch Phys Med Rehabil. [Internet].; 2016;98(6):1126-1131 [acesso em: 03 set 2018]. Disponível em: https://doi.org/10.1016/i.apmr.2016.10.015.

16. Alvarez AB, Teixeira MLO, Branco EMSC, Machado WCA. Sentimentos de clientes paraplégicos com lesão medular e cuidadores: implicações para o cuidado de enfermagem. Ciênc Cuid Saúde [Internet].; 2013;12(4):654-651 [acesso em: 10 dez 2017]. Disponível em: http://dx.doi.org/10.4025/cienccuidsaude.v12i4.18107

17. Trierveiler KS, Ramos FRS, Schoeller SD, Nogueira GC, Martins MMFPS, Schneider DG. Funcionalidade familiar da pessoa com lesão medular. Texto Contexto Enferm [Internet].; 2015;24(4):993-1002 [acesso em: 05 jan 2017]. Disponível em:

http://dx.doi.org/10.1590/0104-0707201500003610014.

18. Santos JVP, Santos TLB, Souza AAA, Veronese RB. Políticas de inclusão de pessoas com deficiência no mercado de trabalho: uma análise sobre o caso de lavras (mg). Rev. FOCO [Internet].; 2015;8(2):4-15 [acesso em: 15 out 2017]. Disponível em:

https://doi.org/10.28950/1981-223x revistafocoadm/2015.v8i2.173.

19. Instituto Brasileiro de Geografia e Estatística (IBGE). Censo demográfico 2010: características gerais da população, religião e pessoas com deficiência [Internet].; 2010 [acesso em: 19 ago 2017] 2017. Disponível em:

http://www.ibge.gov.br/home/estatistica/populacao/censo2010/caracteristicas religiao deficiencia/default caracteristicas religia o deficiencia.shtm.

20. Rowell D, Connelly L. Labour market outcomes for people with a spinal cord injury. Econ. Hum. Biol [Internet].; 2010;8:223-232 [acesso em: 26 mar 2018]. Disponível em: https://doi.org/10.1016/j.ehb.2010.05.003

21. Vilela LO, Leite LP. Effects of an intervention on the participation of people with disability in the workplace. Estud. psicol. [Internet].; 2017;34(1):1-12 [acesso em: 03 set 2018]. Disponível em: http://dx.doi.org/10.1590/1982-02752017000100018. 22. Cavalcante ES, Pessoa Júnior JM, Freire ILS, Cavalcante CAA, Miranda FAN. Representações sociais de pescadores com lesão medular: repercussões e trajetória de vida. Rev. Bras. Enferm [Internet].; 2017;70(1):139-145 [acesso em: 19 dez 2017]. Disponível em: http://dx.doi.org/10.1590/0034-7167-2016-0436 
23. Rodrigues FR, Haidar Filho A, Haidar AM, Soares KVBC, Carvalho STRF. Qualidade de vida de indivíduos com lesão medular praticantes de basquetebol em cadeira de rodas. CEUMA Perspect [Internet].; 2016;27(1):94-102 [acesso em: 30 nov2017]. Disponível em: http://www.ceuma.br/portalderevistas/index.php/RCCP/article/view/44/43

24. Zwierzchowska A, Żebrowska A, Szkwara M. Sports activities and satisfaction of living of men after cervical spinal cord injury. Polish Annals of Medic. [Internet].; 2017;24(2):205-208 [acesso em: 03 set 2018]. Disponível em:

https://doi.org/10.1016/i.poamed.2017.03.009. 